\title{
Editorial
}

\section{When should patients with acute myocardial infarction be transferred for primary angioplasty?}

The results of several randomised trials have shown superior outcomes with primary angioplasty for acute myocardial infarction compared to thrombolytic treatment. ${ }^{1-4}$ Primary angioplasty establishes TIMI-3 flow in the infarct artery in $93-97 \%$ of patients ${ }^{15}$ compared with $54 \%$ with accelerated t-PA. ${ }^{6}$ Pooled data from three randomised trials have shown lower hospital mortality $(2.2 \%$ v $5.9 \%$, $\mathrm{p}=0.02)$ and less non-fatal re-infarction $(1.9 \% v 8.1 \%$, $\mathrm{p}=0.001)$ in patients treated with primary angioplasty versus thrombolytic treatment. ${ }^{1-3}$ Intracranial haemorrhage, the most feared complication of thrombolysis, occurred significantly less often with primary angioplasty versus t-PA in both the PAMI-1 trial $(0 \%$ v $2.0 \%$, $\mathrm{p}=0.05)^{1}$ and the GUSTO-IIB trial $(0 \%$ v $1.4 \%$, $\mathrm{p}=0.008) .{ }^{4}$ In addition, several studies have documented shorter hospital stay and comparable or lower hospital costs with primary angioplasty. ${ }^{7-9}$ Because of these data, primary angioplasty has emerged as the preferred reperfusion strategy for acute myocardial infarction in institutions with interventional facilities and skilled operators.

\section{Limited availability of primary angioplasty}

The use of primary angioplasty is limited by the availability of facilities and technical staff to perform coronary interventional procedures. Fewer than $20 \%$ of hospitals in the United States, and fewer than $10 \%$ of hospitals in Europe have facilities to perform angioplasty, and not all of these institutions are prepared to perform the procedure on an emergency basis. ${ }^{10}$ While the use of primary angioplasty is increasing, the Second National Registry of Myocardial Infarction documented in 1995-96 that only $14 \%$ of patients treated with reperfusion therapy in the United States were treated with primary angioplasty. ${ }^{10}$ Most patients with acute myocardial infarction present to community hospitals where angioplasty is not available, and these patients would need to be transported to an interventional facility to be treated with primary angioplasty. The time required to transfer these patients delays the onset of reperfusion and could negate part or all of the benefit that primary angioplasty has over thrombolytic therapy.

\section{How important is time to treatment?}

The benefit of thrombolysis for acute myocardial infarction is strongly dependent on the time delay from symptom onset until treatment. ${ }^{112}$ This raises concerns about delaying reperfusion to transport a patient to an interventional facility from a community hospital. However, the time delay from symptom onset until treatment may be less important with primary angioplasty than with thrombolytic therapy. The PAMI-2 investigators found that hospital mortality with primary angioplasty, unlike thrombolytic treatment, remained very low and fairly constant from $2-12$ hours after the onset of symptoms (fig 1). ${ }^{13}$ This may be explained in part by the fact that TIMI-3 flow was established with similar rates (88-95\%), regardless of the time delay, up to 12 hours from the onset of symptoms. This is unlike thrombolytic treatment where reperfusion

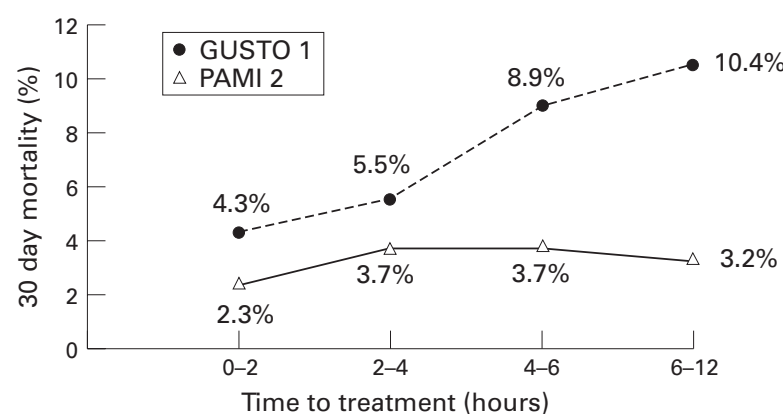

Figure 1 Mortality (30 day) versus time to treatment with accelerated $t-P A(G U S T O-1)^{12}$ and primary angioplasty (PAMI-2). ${ }^{13}$ In-hospital mortality increases with increasing time to treatment with $t-P A$, but is relatively flat from 2-12 hours with primary angioplasty.

rates decrease with increasing time to treatment. ${ }^{14}$ These data suggest that the time delay inherent in transferring patients to tertiary centres for primary angioplasty may not be prohibitive.

\section{Transferring patients for primary angioplasty}

Ziljstra and colleagues, in this issue, ${ }^{15}$ have offered some insights into the feasibility of transferring patients with acute myocardial infarction from the community hospital to an interventional facility to perform primary angioplasty. In 104 high risk patients transferred from community hospitals, the authors found the risk of transport to be low and the effect on total ischaemic time to be limited. The mean transport time, defined as the time from admission to the community hospital until admission to the interventional hospital, was 70 minutes. Part of this time (28 minutes) was countered by more rapid in-hospital transfer to the catheterisation laboratory, so that the mean net delay in the "door to balloon" time was 42 minutes. Outcomes in patients who were transferred from community hospitals and patients who were admitted to the interventional hospital were similar. Although, these comparisons are limited by small numbers and selection bias, they do not suggest adverse outcomes in transferred patients.

The PAMI-2 trial had similar findings. Outcomes in 80 patients referred from community hospitals to two interventional institutions for primary angioplasty were similar to outcomes in non-transferred patients (Byrne TJ, personal communication, 1995).

\section{The need for randomised trials}

Currently, there are no randomised data to determine whether it is better to give thrombolytic treatment at the community hospital or transfer patients to interventional facilities for primary angioplasty. Which patients will be most suitable for transfer (high risk patients only or all patients), and how much delay is too much, are unknown. There are currently at least two randomised trials designed to answer these questions. The PAMI group has an ongoing randomised trial (AIR-PAMI) to test the hypothesis that outcomes in high risk acute myocardial infarction patients transferred for primary angioplasty, when there is 
up to two hours of transport delay, will be superior to thrombolytic treatment given at the local hospital. Likewise, Ziljstra and colleagues indicate that a similar trial is planned in the Netherlands. Hopefully the results of these trials will answer these important questions.

Until we have the results of these trials, the clinician must decide whether patients should be transferred from the community hospital for primary angioplasty based on the available limited data. Patients with cardiogenic shock have shown little or no benefit from thrombolytic treatment and appear to have substantial survival benefit with primary angioplasty. It seems appropriate to transfer these patients for primary angioplasty. Patients who are not eligible for thrombolysis because of increased risk of bleeding, and who would not receive reperfusion therapy in hospitals without primary angioplasty, are also good candidates for transfer. High risk patients (patients $>70$ years, patients with anterior wall myocardial infarction or congestive heart failure) who have the greatest potential mortality benefit from primary angioplasty versus thrombolytic treatment may be candidates for transfer depending on the delay. If reperfusion can be expected to be obtained within 90 minutes of the diagnosis, it seems reasonable to transfer these patients for primary angioplasty. This is based on the American College of Cardiology-American Heart Association guidelines recommending a class I indication for primary angioplasty if it can be performed by experienced personnel within 90 minutes of diagnosis. ${ }^{16}$ In low risk patients, or if longer delays are expected, patients should be given thrombolytic agents at the local hospital until there is information from randomised trials.

Moses H Cone Memorial Hospital,

BRUCE R BRODIE

Greensboro, NC 27408, USA

1 Grines CL, Browne KF, Marco J, Rothbaum B, Stone GW, O'Keefe J, et al. A comparison of immediate angioplasty with thrombolytic therapy for acute myocardial infarction. $N$ Engl $\mathcal{F}$ Med 1993;328:673-9.
2 Ziljstra F, Jan De Boer M, Hoorntje JCA, Reiffers S, Reiber JHC, Suryapranata H. A comparison of immediate coronary angioplasty with intravenous

3 Gibbons RJ, Holmes DR, Reeder GS, Bailey KR, Hopsenspirger MR, Gersh BJ. Immediate angioplasty compared with the administration of a thrombolytic agent followed by conservative treatment for myocardial infarction. N Engl f Med 1993;328:685-91.

4 Ellis S. GUSTO-IIB substudy: primary angioplasty versus thrombolysis [abstract]. 45th Annual Scientific Session of the American College of Cardiology, Orlando, Florida, March 1996.

5 O'Neill WW, Brodie BR, Ivanhoe R, Knopf W, Taylor G, O'Keefe J, et al. Primary coronary angioplasty for acute myocardial infarction (the primary angioplasty registry). Am $\mathcal{f}$ Cardiol 1994;73:627-34.

6 The GUSTO Angiographic Investigators. The effects of tissue plasminogen activator, streptokinase, or both on coronary artery patency, ventricular function, and survival

7 Reeder GS, Bailey KR, Gersh BJ, Holmes DR, Christianson J, Gibbons RJ. Cost comparison of immediate angioplasty versus thrombolysis followed by conservative therapy for acute myocardial infarction: a randomized prospective trial. Mayo Clin Proc 1994;69:5-12.

8 Stone GW, Grines CL, Rothbaum B, Catlin T, O’Neill WW. Primary angioplasty reduces hospital costs while improving outcomes in AMIcomprehensive cost efficacy analysis from the PAMI study [abstract]. Circulation 1996;94:I330.

9 Mark DD, Granger CB, Ellis SG, Phillips HR, Knight D, Davidson-Ray L, et al. Costs of direct angioplasty versus thrombolysis for acute myocardial infarction: results from the GUSTO II randomized trial [abstract]. Circulainfarction: results 1996 ; 94 :I168.

10 Lange RA, Hillis LD. Should thrombolysis or primary angioplasty be the treatment of choice for acute myocardial infarction? $N$ Engl 7 Med treatment of choice for acute myocardial infarction? $N$ Engl f Med Registry of Myocardial Infarction-2, November 1996, Chicago, Illinois.)

11 Gruppo Italiano per lo Studio della Streptochinasi nell'infarto Miocardico (GISSI). Effectiveness of intravenous thrombolytic treatment in acute myocardial infarction. Lancet 1986;i:397-401.

12 The GUSTO Investigators. An international trial comparing four thrombolytic strategies for acute myocardial infarction. $N$ Engl f Med 1993;329: 673-82.

13 Stone GW, Brodie BR, Griffin J, Donohue B, Costantini C, Jones D, et al. Should the risk of delaying reperfusion prohibit inter-hospital transfer to perform primary PTCA in acute myocardial infarction? [abstract] Circulation 1996;94:I330.

14 Chesebro JH, Knatterud G, Roberts R, Borer J, Cohen LS, Dalen J, et al. Thrombolysis in myocardial infarctions (TIMI) trial, phase I: a comparison between intravenous tissue plasminogen activator and intravenous between intravenous tissue plasminog

15 Zijlstra F, van't Hof AWJ, Liem AL, Hoorntje JCA, Suryapranata H, de Boer Zijlstra F, van't Hof AWJ, Liem AL, Hoorntje JCA, Suryapranata H, de Boer
M-J. Transferring patients for primary angioplasty: a retrospective analysis of 104 selected high risk patients with acute myocardial infarction. Heart 1997;78:333-6.

16 Committee on Practice Guidelines for the Management of Acute Myocardial Infarction. ACC/AHA guidelines for the management of patients with acute myocardial infarction. F Am Coll Cardiol 1996;28:1328428. 